\title{
Factors associated with Genital Hygiene Behaviours in pregnant and non-pregnant women in Turkey ${ }^{1}$
}

\author{
Seyhan Çankaya ${ }^{2}$ \\ Sema Dereli Yilmaz
}

\begin{abstract}
Purpose: This descriptive study was conducted to determine the factors associated with genital hygiene behaviours in pregnant and non-pregnant women.

Method and material: Seventy pregnant women and 70 non-pregnant women, aged between 25 and 45 years, who were in the third trimester of pregnancy and presented to the Gynecology and Obstetrics Clinic at the Faculty of Medicine in Konya Province, Turkey, were included in the study. The data were gathered using a questionnaire with 26 questions designed by the researcher using the Genital Hygiene Behavior Inventory (GHBI).

Results: There was no significant difference between the GHBI scores of the pregnant and nonpregnant women $(\mathrm{p}>0.05)$. Therefore, both groups were combined, and it was aimed to discover the factors associated with genital hygiene behaviours more effectively. A positive correlation between the GHBI scores and the monthly income was found, whereas there was a negative correlation between the GHBI scores and age, marriage age, number of pregnancies, and birth $(\mathrm{p}<0.05)$. There was a significant difference between the GHBI scores and the educational status of the women and their husbands, the employment status of the women and the perceived income status $(p<0.05)$. A statistically significant difference was found between the groups in terms of GHBI scores and the women's pain and/or bleeding experience during sexual intercourse, vaginal douching, and training on the hygiene of the genital area $(\mathrm{p}<0.05)$.

Conclusion: There was no significant difference in genital hygiene behaviours between the pregnant and non-pregnant women. This may be attributed to the fact that the genital hygiene practices of women who did not have sufficient knowledge of genital hygiene before they became pregnant did not change during pregnancy. Therefore, we suggest that midwives provide both pregnant and non-pregnant women with training on genital hygiene.
\end{abstract}

Keywords: Behaviour; pregnancy; genital hygiene; genital infections; women's health.

\footnotetext{
1 This study was presented as a oral presentation at $3^{\text {rd }}$ National- $2^{\text {nd }}$ International Midwifery Congress, Oral Presentation, 20-23 November, Antalya/Turkey, 2013.

2 Ph.D., Lecturer, Midwifery Department, Health Sciences Faculty of Selcuk University, seyhancankaya@selcuk.edu.tr

${ }^{3}$ Assoc. Prof. Dr., Midwifery Department, Health Sciences Faculty of Selcuk University, syilmaz33@gmail.com
} 
Çankaya, S., \& Dereli Yllmaz, S. (2015). Factors associated with Genital Hygiene Behaviours in pregnant and nonpregnant women in Turkey. International Journal of Human Sciences, 12(1), 920-932. doi: 10.14687/ijhs.v12i1.3126

\section{Introduction}

Genital hygiene behaviours are influenced by knowledge, beliefs, and habits, with the ultimate goal of improving social well-being, comfort, and health (Fakhri, Hamzehgardeshi, Hajikhani \& Komili, 2012; Dongre, Deshmukh \& Garg, 2007). In addition, these behaviours are known to differ from one individual to another. Previous studies suggest that genital hygiene care is of great importance in the prevention of infections, as poor genital hygiene may cause genital infections and frequent abnormal genital discharge (Dongre, Deshmukh \& Garg, 2007; Ege \& Eryllmaz, 2006). Genital hygiene care may be affected by environmental and personal factors, among many others. The most important environmental factor is socioeconomic status, while the leading personal factor is poor hygiene habits. Moreover, poor hand-washing habits, improper cleaning of the genital area after using the toilet, not wearing proper underclothes, and poor menstrual hygiene may increase the risk for genital infections (Ott, Ofner \& Fortenberry, 2009).

The high prevalence of genital infections is due to such reasons as a lack of genital hygiene knowledge, incorrect genital hygiene beliefs and behaviours, non-systematic health education, and a lack of medical examinations for genital health problems (Nair et al., 2006; Garg, Goyal \& Gupta, 2012). Risky hygiene behaviours that may result in genital infections are common among Turkish women, with most women of reproductive age experiencing vaginal discharge due to vaginal infections at least once in their life (Farage, Lennon \& Ajayi, 2011).

Pregnancy is associated with both physical and psychological changes. During this period, significant changes occur in the vaginal area, which increase susceptibility to vaginal infections. If left untreated, vaginal infections due to poor genital hygiene during pregnancy may potentially harm the foetus, and predispose to complications such as pelvic inflammatory disease, which may lead to infertility (Cottrell, 2010). Therefore, preventive measures are essential in the provision of early diagnosis and treatment services, which will ultimately ensure the protection and improvement of maternal-foetal health (Chalermchockchareonkit, Phoethong, Ruangvutilert \& Thamkhantho, 2013; Plumb \& Clayton, 2013).

Abnormal vaginal discharge is a common complaint among women in countries such as India, Kenya, and Turkey (Patel et al., 2006; Fonck et al., 2000; Polat, et al., 2011). Therefore, a study of genital hygiene behaviours may contribute to reducing these complaints, improving reproductive health, and ensuring that the necessary measures are put in place to improve genital hygiene behaviours. The study will also determine pregnant women's awareness of genital hygiene care and its importance for reproductive and foetal health. Finally, an investigation of differences in genital hygiene behaviours between pregnant and non-pregnant women in society are of high importance 
Çankaya, S., \& Dereli Yllmaz, S. (2015). Factors associated with Genital Hygiene Behaviours in pregnant and nonpregnant women in Turkey. International Journal of Human Sciences, 12(1), 920-932. doi: 10.14687/ijhs.v12i1.3126

in planning the required midwifery interventions and in improving strategies used to prevent vaginal infections.

\section{Purpose}

This research was conducted to determine the genital hygiene behaviours of pregnant and non-pregnant women, and to establish a correlation with factors known to affect these behaviours.

\section{Method and material}

\subsection{The place of the study}

The study was undertaken at obstetric and gynaecology polyclinics of an university hospital in Konya.

\subsection{Population and sample selection}

The Genital Hygiene Behavior Inventory (GHBI) was used to determine mean (SD) scores for the pregnant women (82 (12)) and non-pregnant women (73 (12)), and to determine the sample size (Kavlak, Saruhan, Er, Şen \& Sevil, 2012; Ege \& Eryılmaz, 2006). The expected difference between scores associated with the genital hygiene behaviours of the pregnant and non-pregnant women was estimated using G*Power 3.1 with $80 \%$ power and $95 \%$ confidence intervals $(n=29$, for both groups). Because the data were to be randomly collected from one of the five state hospitals in Konya Province, the design effect was found to be 2.4 and it was decided that 70 (calculated using the following formula: $29 \times 2.4=70$ ) women for the pregnant women group and another 70 (calculated using the following formula: $29 \times 2.4=70$ ) women for the non-pregnant women group would be included in the sample.

The random sampling method of non-probability sampling methods was used for data collection. Study participants were women aged 25-49 years who admitted to the obstetrics and gynaecology polyclinics.

\section{Inclusion Criteria}

\section{Criteria to be met by the pregnant women:}

Being between 25 and 49 years old, being in the third trimester, being multigravida, having at least a primary school degree, still living with a sexual partner, not having a systemic disease, not having any communication problem (such as hearing and visual impairments), having an income equal to at least the minimum wage level, living in a city centre.

\section{Criteria to be met by the non-pregnant women:}


Çankaya, S., \& Dereli Yllmaz, S. (2015). Factors associated with Genital Hygiene Behaviours in pregnant and nonpregnant women in Turkey. International Journal of Human Sciences, 12(1), 920-932. doi: 10.14687/ijhs.v12i1.3126

Not being pregnant, being between 25 and 49 years old, having at least a primary school degree, still living with a sexual partner, having given birth at least once, not having a systemic disease, not having any communication problem (such as hearing and visual impairments), not having commenced menopause, having an income equal at least to minimum wage level, living in a city centre.

\subsection{Type of study}

This is a descriptive and comparative study.

\subsection{The variables}

Dependent variable of the research is Genital Hygiene Behavior Inventory (GHBI) while the independent variables are sociodemographic characteristics of pregnant and non-pregnant women

\subsection{Data Collection}

\subsubsection{Data collection method}

The data of the research were collected through face-to-face interviews.

\subsubsection{Data collection tools}

Data were collected via a questionnaire prepared by researchers and consisting of 26 questions that addressed socio-demographic and obstetric characteristics, as well as vaginal infection or infection status, and GHBI (Kavlak, Saruhan, Er, Şen \& Sevil, 2012; Ege \& Eryllmaz, 2006).

The GHBI is a four-point, Likert type, measurement inventory developed by Ege and Eryilmaz (2006) to be used in studies of the genital hygiene behaviours of sexually active women aged 15-49 years.. The inventory is composed of 27 items and one dimension. The lowest score that can be obtained from the inventory is 27 , whereas the highest score is 108 . A higher total score indicates that genital hygiene behaviours are satisfactory. The Cronbach alpha reliability coefficient of the inventory was $a=0.86$ (Ege \& Eryllmaz, 2006). In this study, it was estimated as $a=0.79$.

\subsubsection{Data collection time}

Data were collected between January 2012 and April 2012.

\subsection{Limitations of the study}

The study has some limitations. First, the results cannot be generalized because the sample size is small, the study was conducted at a hospital and answers were self-reportedly given. Therefore; multicentric studies with large sample sizes are required. Also; the group of pregnant women and the group of non-pregnant women were united and thus analyzed in order 
Çankaya, S., \& Dereli Yllmaz, S. (2015). Factors associated with Genital Hygiene Behaviours in pregnant and nonpregnant women in Turkey. International Journal of Human Sciences, 12(1), 920-932. doi: 10.14687/ijhs.v12i1.3126

to determine the factors correlated with GHBI score; thus both sample size was enlarged and the factors correlated with GHBI among the women in the society were aimed.

\subsection{Research ethics}

To perform the study, an approval was obtained from the ethical board of Selcuk University. The participants were verbally informed of the purpose of the research and were asked to provide written and verbal informed consent prior to filling out the questionnaires. The self-report data were collected by the researcher in a private room.

\subsection{Evaluation of data}

The SSPS program was used for statistical analyses of the data. Appropriateness of variables to normal distribution rates was investigated with visual and analytic methods. Descriptive statistics were evaluated with numbers, percentages, means, and standard deviations. The Mann-Whitney $U$ test and Kruskal-Wallis variance analysis were used to compare the independent variables. Post hoc analyses were performed using the Bonferroni-corrected Mann-Whitney $U$ test. The analysis showed no significant difference between the GHBI scores of the pregnant and non-pregnant women; therefore, the data of all the women were compared without being classified into groups and analyses were performed using the combined data of the 140 women in terms of the GHBI scores obtained for the variables concerning socio-demographic and obstetric characteristics, and genitourinary infections.

\section{Results}

The mean age of the study participants was 31.06 (4.89) years, the mean marriage age was 10.19 (6.44) years, the mean number of pregnancies and births was 2.84 (1.45) and 1.94 (SD 1.13), respectively. - Of the participants, $77 \%$ lived in a nuclear family, and $93.6 \%$ received social security benefits. The mean gestational age of the pregnant women was 32.59 (4.17) weeks, and the number of medical appointments during pregnancy was 11.34 (7.17). Among the women, 17.1\% had a previous abortion, $30 \%$ had a previous miscarriage, $24.3 \%$ had unintended pregnancies, and $60 \%$ used modern family planning methods. It was found that $17.1 \%$ of the non-pregnant women had previous abortions, and $74.3 \%$ used modern family planning methods.

It was noted that $35.7 \%$ of the pregnant women had genital infections during pregnancy and $72 \%$ consulted physicians for genital infections, while 16\% decided to leave the infections untreated. As for the non-pregnant women, $41.4 \%$ had had urinary tract infections in the most recent year and 58.6\% consulted physicians for urinary tract infections. Of the non-pregnant women, $40 \%$ had genital infections in the recent year and $22.9 \%$ had genital infections during the 
Çankaya, S., \& Dereli Yllmaz, S. (2015). Factors associated with Genital Hygiene Behaviours in pregnant and nonpregnant women in Turkey. International Journal of Human Sciences, 12(1), 920-932. doi: 10.14687/ijhs.v12i1.3126

study, $60.7 \%$ sought medical advice for genital infections, and $21.4 \%$ decided to leave the infections untreated.

The GHBI scores were 74.87 (11.08) and 75.01 (11.63) among the pregnant and non-pregnant women, respectively. The statistical analyses showed no statistically significant difference in mean GHBI score between the pregnant and non-pregnant women $(p>0.05$; Table 1).

Table 1: Comparison of GHBI scores between the pregnant and non-pregnant women.

\begin{tabular}{llll}
\hline & \multicolumn{1}{l}{ GHBI Total Score } & Z & $\boldsymbol{P}$ \\
& $(\mathrm{SD})$ & & \\
\hline $\begin{array}{l}\text { Pregnant women }(\mathbf{n}=\mathbf{7 0}) \\
\text { Non-pregnant women }\end{array}$ & $74.87(11.08)$ & -0.206 & 0.836 \\
$(\mathbf{n}=70)$ & $75.01(11.63)$ & & \\
\hline
\end{tabular}

It was detected that there was a positive correlation $\left(r_{\mathrm{s}}=0.362\right)$ between the GHBI scores and the monthly income. However, there was a negative and moderate correlation $\left(r_{\mathrm{s}}=-0.321\right)$ between the GHBI scores and the number of pregnancies, and a negative and low correlation between the GHBI scores and age $\left(r_{\mathrm{s}}=-0.255\right)$, marriage age $\left(r_{\mathrm{s}}=-0.212\right)$ and number of births $\left(r_{\mathrm{s}}=-0.225 ; p<0.05\right.$; Table 2$)$.

Table 2: Correlation analysis between socio-demographic and obstetric characteristics of the women, and GHBI scores ( $\mathrm{n}=140)$

\section{GHBI}

\begin{tabular}{lcl}
\hline & $\boldsymbol{r}_{\mathrm{s}}$ & $\boldsymbol{P}$ \\
Age & -0.255 & 0.002 \\
Marriage age & -0.212 & 0.012 \\
Number of pregnancies & -0.321 & $<0.001$ \\
Number of births & -0.225 & $\mathbf{0 . 0 0 7}$ \\
Monthly income & 0.362 & $<0.001$ \\
\hline
\end{tabular}

When some of the socio-demographic characteristics of the women were compared with the GHBI scores, a statistically significant difference was noted among educational statuses of the women and their husbands, women's employment status, and perceived income level in terms of GHBI scores $(p<0.05)$. The post hoc analysis showed that this difference resulted from those who perceived their income as satisfactory. The total GHBI scores of the women who were 
Çankaya, S., \& Dereli Yllmaz, S. (2015). Factors associated with Genital Hygiene Behaviours in pregnant and nonpregnant women in Turkey. International Journal of Human Sciences, 12(1), 920-932. doi: 10.14687/ijhs.v12i1.3126

employed, had secondary school education and higher, whose husband had a secondary school degree and higher, and who perceived their income level as satisfactory were statistically and significantly high $(p<0.05)$. No statistically significant difference was found between the GHBI scores and the place where the women lived most of their life, as well as family type $(p>0.05$; Table 3).

Table 3: Comparison of GHBI scores of all women in terms of socio-demographic characteristics $(\mathrm{n}=140)$

$\begin{array}{lllll}\text { Number } & \text { Percentage } & \text { GHBI } & \text { Z } & p \\ \text { (n) } & (\%) & \text { Mean (SD) } & & \end{array}$

\section{Employment status}

\begin{tabular}{|c|c|c|c|c|}
\hline Employed & 30 & 21.4 & (10.67) & -4.413 \\
\hline Non-employed & 110 & 78.6 & $72.63(10.40)$ & \\
\hline
\end{tabular}

\section{Educational Status}

Primary school degree

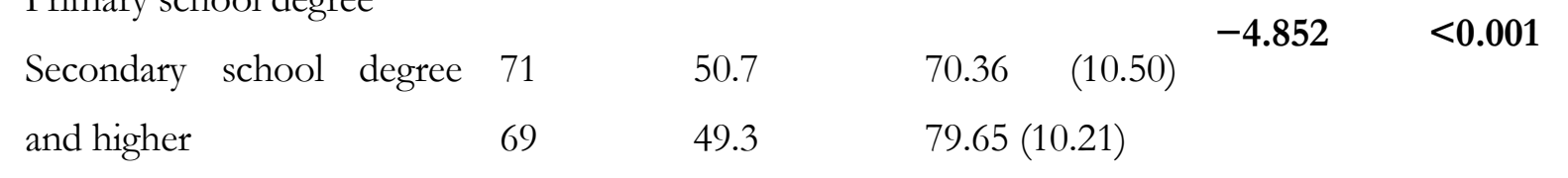

\begin{tabular}{lccccccc}
\hline $\begin{array}{l}\text { Husband's } \\
\text { status }\end{array}$ & & & & & & \\
Primary school & degree & & & & & \\
Secondary & school degree & 61 & 43.6 & 70.83 & $(11.01)$ & & \\
and higher & & 79 & 56.4 & $78.11(10.58)$ & & \\
\hline & & & & & KW & p
\end{tabular}

\section{Income Level}

Satisfactory

$40 \quad 28.6 \quad 79.75(9.81)^{\mathrm{a}, \mathrm{b}}$

Medium

$84 \quad 60.0$

73.33 (11.26)

Non-satisfactory

$16 \quad 11.4$

$71.37(12.12)$

10.814

0.004

${ }^{a}$ For those who perceived income level as medium, $p<0.017$

${ }^{\mathrm{b}}$ For those who perceived income level as bad, $p<0.017$

It was found that there was a statistically significant difference between GHBI scores and pain and/or bleeding during sexual intercourse, vaginal douching, and training about genital area cleaning $(\phi<0.05)$ (Table 4). 
Çankaya, S., \& Dereli Yllmaz, S. (2015). Factors associated with Genital Hygiene Behaviours in pregnant and nonpregnant women in Turkey. International Journal of Human Sciences, 12(1), 920-932. doi: 10.14687/ijhs.v12i1.3126

Table 4: Comparison of GHBI scores of all women in terms of genitourinary infection features $(n=140)$

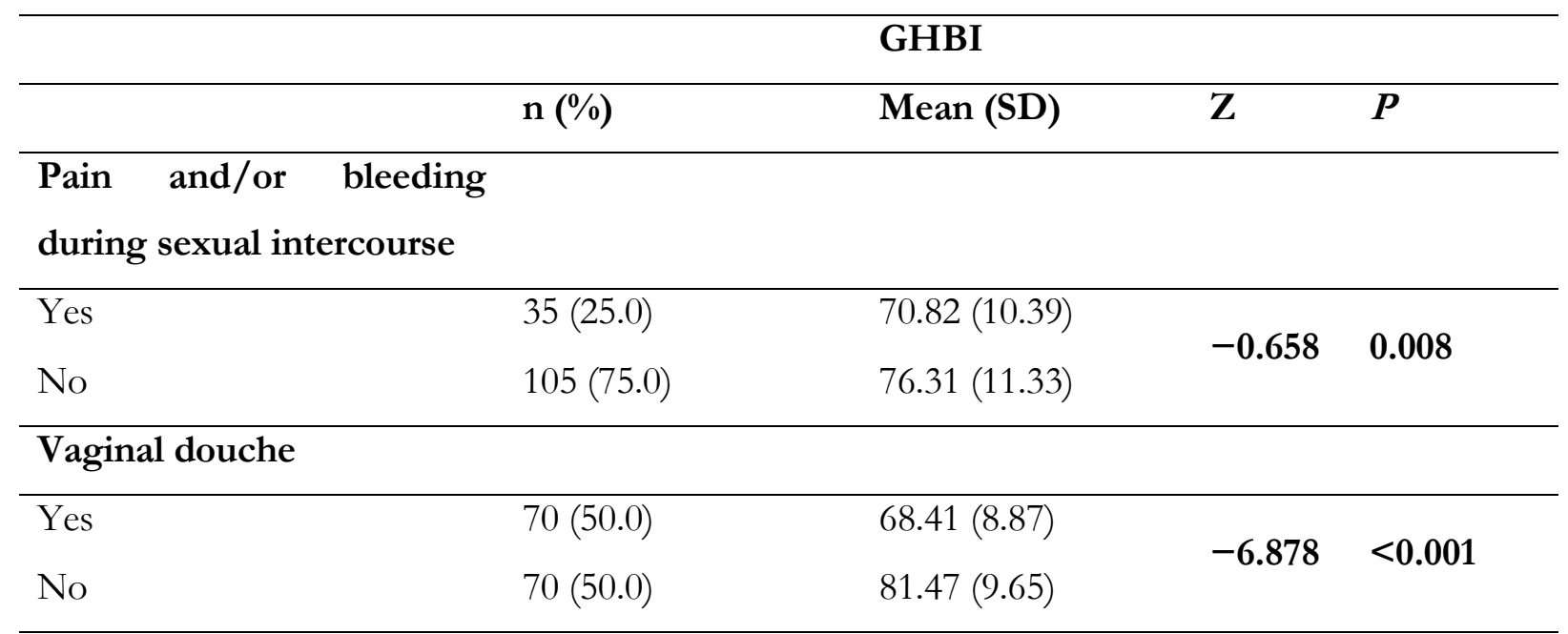

When do they have a

vaginal douche?*

After sexual intercourse

$21(15.0)$

$70.71(9.27)$

After sexual intercourse and

post menstruation

$49(35.0) \quad 67.54(8.55)$

$-1.394 \quad 0.163$

Whether or not having

training about cleaning of

the genital area previously

$\begin{array}{lllll}\text { No } & 101(72.1) & 71.76(9.95) & \mathbf{- 5 . 1 9 0} & <\mathbf{0 . 0 0 1} \\ \text { Yes } & 39(27.9) & 83.18(10.58) & & \end{array}$

*Those who had vaginal douches were analysed.

\section{Discussion}

The present study aimed to determine the genital hygiene behaviours of pregnant and nonpregnant women and the correlation between these practices and several factors affecting genital hygiene. The GHBI scores of the pregnant and non-pregnant women were found to be similar. This finding was important because it proved that behaviours adopted before pregnancy continued after pregnancy and that pregnancies did not lead to any change in genital hygiene behaviours. We suspected that women who did not have sufficient knowledge and awareness of genital hygiene before becoming pregnant did not understand the importance of genital hygiene during pregnancy, resulting in poor genital hygiene practices. Therefore, we suggested that midwives should provide both pregnant and non-pregnant women with genital hygiene education and support. 
Çankaya, S., \& Dereli Y1lmaz, S. (2015). Factors associated with Genital Hygiene Behaviours in pregnant and nonpregnant women in Turkey. International Journal of Human Sciences, 12(1), 920-932. doi: 10.14687/ijhs.v12i1.3126

Because there was no difference in terms of GHBI scores between pregnant and nonpregnant women, the subsequent analyses combined the data of all women in the study to allow a more precise analysis of the factors correlated with GHBI scores. This analysis showed that GHBI scores increased as the women's age and marriage age decreased. These findings were confirmed by those of Polat et al. (2011) and Yasmin \& Mukherjee, (2012) that showed that the incidence of genital infections increased with age and marriage age. In addition, T. vaginalis infections were reported to be more common during the ages of 30-40 years, the sexually active period (Ramia, et al., 2012). Another study reported no correlation between mean GHBI scores and women's ages (Ege \& Eryllmaz, 2006). In addition to this study, another study conducted with 134 pregnant women in Izmir revealed that there was no correlation between mean GHBI scores and women's ages (Kavlak, Saruhan, Er, Şen \& Sevil, 2012). The differences seen here may be attributed to these studies being conducted in regions with different socio-cultural and economic features, resulting in increased mean GHBI scores due to young women having improved access to information.

High fertility and increased number of pregnancies increase mortality and morbidity, malnutrition, and birth complications, and pave the way for genital infections by affecting reproductive health negatively. ${ }^{8}$ Some studies have reported that as the number of births increases, so does the risk for vaginal infections $(p<0.05)$ (Patel, et al., 2006; Prasad, et al., 2011). The study of Kavlak, et al. (2012) reported that there was a negatively low and significant correlation between GHBI scores and number of pregnancies. The study of Er \& Sirin (2007) showed that scores obtained from the Scale of Health Behaviours during Pregnancy (SHBP) decreased as the number of pregnancies increased (Er \& Şirin, 2007). Our study findings support the current results in the literature, including those from the study of Kavlak et al. (2012). Therefore, we attributed the lower GHBI scores associated with a higher number of pregnancies to the possibility that meticulousness, attention, and delicacy shown by women during early pregnancies gradually decreases with subsequent pregnancies, which affects their GHBI behaviours negatively.

In our study, a significant positive correlation between the mean monthly income and the mean GHBI scores was noted $(p<0.05)$. However, there are conflicting results concerning this finding. One study reported a significant correlation between the mean monthly income and mean GHBI scores (Ocaktan, Baran \& Akdur, 2010), whereas other studies reported no significant correlation between these two variables (Kavlak, Saruhan, Er, Şen \& Sevil, 2012; Ege \& Eryılmaz, 2006). We argued that the fact that women who had satisfactory monthly income had high GHBI scores may be related to good living conditions early in their life, which allowed improved access to health-care services and resulted in improved hygienic conditions associated with a higher economic status. 
Çankaya, S., \& Dereli Yılmaz, S. (2015). Factors associated with Genital Hygiene Behaviours in pregnant and nonpregnant women in Turkey. International Journal of Human Sciences, 12(1), 920-932. doi: 10.14687/ijhs.v12i1.3126

The social status, educational levels, and levels of self-care among Turkish women have been reported to be low (Ferraro, Boehm, Gaudet \& Adamo, 2013). That working women have better opportunities to use health services may affect their hygiene habits positively. Similar to other studies, our study shows that GHBI scores were higher in the working women (Ege \& Eryllmaz, 2006; Cankaya \& Ege, 2014). Furthermore, Kısa \& Taşkın (2009) reported that vaginal infection risk was 2.5 times higher among non-working women. In the study of Kavlak et al. (2012) no significant correlation was found between employment status and GHBI scores of pregnant women. The positive correlation between employment status and improved genital hygiene behaviours in working women may be due to greater social interaction and improved economic status.

Given that factors such as low socio-economic status, an inability to perform hygienic activities, increased fertility, malnutrition, and lack of knowledge are more common among women with low educational status, our study aimed to determine the correlation between educational status and vaginal infections. In the present study, we found that the educational status of the women was correlated with their mean GHBI scores.

Similar to our study, previous studies conducted with both pregnant women and women of reproductive age have shown that a higher educational status was associated with higher mean GHBI scores, and SHBP scores and status, as well as better genital hygiene behaviours during pregnancy (Ege \& Eryllmaz, 2006; Kavlak, Saruhan, Er, Şen \& Sevil, 2012; Dwyer, 2001). Some studies have reported that there was no correlation between educational status and vaginal infections, and that the risk for vaginal infections was lower among illiterate women (Patel, et al., 2006; Polat, et al., 2011). By contrast, other studies have reported that women who had received at least a high school education demonstrated better genital hygiene behavioursand had a lower risk of vaginal infections (Cankaya \& Ege, 2014; Hacialioğlu, Nazik \& Kiliç, 2009; Bradshaw, et al., 2005). Therefore, education is an important factor associated with women's health, with higher educational levels tending to be associated with positive behaviours.

Similar to other studies, the GHBI scores of the women in our study whose husbands had primary school education were rather low (Ege \& Eryllmaz, 2006; Kisa \& Taskin, 2009). Because the socio-economic and educational statuses of the women whose husbands had a low educational status were low, we argued that these findings were associated with factors such as unhygienic conditions, lack of knowledge, and malnutrition.

In our study, the GHBI scores of the women who perceived their mean monthly income as satisfactory were higher than those who perceived it as being medium or unsatisfactory. Other studies conducted with pregnant women reported that participants with high income levels had 
Çankaya, S., \& Dereli Yllmaz, S. (2015). Factors associated with Genital Hygiene Behaviours in pregnant and nonpregnant women in Turkey. International Journal of Human Sciences, 12(1), 920-932. doi: 10.14687/ijhs.v12i1.3126

high GHBI scores (Polat, et al., 2011; Cankaya \& Ege, 2014). We concluded that economical status may affect women's and their families' ability to access health-care services, nutrition, hygiene habits, substance use like smoking and alcohol intake, intra-family relations, and stress status.

The rate of vaginal douching in Turkish women has been reported as ranging between $38.5 \%$ and 70.6\% (Cankaya \& Ege, 2014; Hacialioğlu, Nazik \& Kiliç, 2009). In our study, the behaviour of vaginal douching was correlated with higher mean GHBI scores, suggesting that a lack of knowledge about vaginal douching may have resulted in the adoption of other negative behaviours. In addition, pain and/or bleeding complaints during sexual intercourse were correlated with lower mean GHBI scores. Previous studies have reported that vaginal douching is associated with an increased risk of serious health problems such as vaginal infections, an increased amount of vaginal discharge, bad odour, vaginal itching and pain, redness in the genital area, complaints of pain in the sub-abdominal area, bacterial vaginosis, ectopic pregnancy, low birth weight, preterm birth, sexually transmitted diseases, cervical cancer, and pelvic inflammatory disease (Kisa \& Taskin, 2009; Ege, Timur, Zincir, Egri Sunar \& Reeder, 2007). Although vaginal douching may lead to numerous health problems, it is a commonly used behaviour worldwide. Many Turkish women perform vaginal douching to eliminate bad vaginal odours after menstruation and prevent pregnancy after sexual intercourse, as they believe that cleanliness after sexual intercourse cannot be achieved with full ablution (Ege \& Eryılmaz, 2006; Ege, Timur, Zincir, Egri Sunar \& Reeder, 2007), whereas women in other countries often consider vaginal douching as a part of female hygiene (McClelland, Ndinya-Achola \& Baeten, 2006; Annang, Grimley \& Hook, 2006).

The low rate of vaginal douching, high rate of complaints related to pain/bleeding complaints during sexual intercourse, and low GHBI scores may be correlated with the lack of education and information about genital area cleaning. Karatay \& Özvariş (2006) showed that only $13.2 \%$ of women received education on the predisposing factors for genital infections. Furthermore, studies have shown that genital hygiene education has a positive impact on women's genital hygiene behaviours (Ege \& Eryllmaz, 2006; Kavlak, Saruhan, Er, Şen \& Sevil, 2012). These findings highlight the importance of reproductive health and hygiene education in the prevention of vaginal infections. Therefore, education programs should be planned and included in the educational and health systems.

\section{Conclusions and recommendations}

\subsection{Usability of study results}

Given that no differences were observed between the pregnant and non-pregnant women using the GHBI, our findings suggest that genital hygiene behaviours adopted before pregnancy 
Çankaya, S., \& Dereli Yllmaz, S. (2015). Factors associated with Genital Hygiene Behaviours in pregnant and nonpregnant women in Turkey. International Journal of Human Sciences, 12(1), 920-932. doi: 10.14687/ijhs.v12i1.3126

continued during pregnancy. Therefore, we recommend that nurses and midwives working in primary health-care services discuss genital hygiene behaviours with non-pregnant and pregnant women receiving prenatal services to improve their knowledge of genital hygiene.

\section{Funding}

The study was funded by the Coordinator ship of Scientific Research Projects of Selcuk University, with project No. 12102004.

\section{References}

Annang, L., Grimley, D. M., Hook, E. W. (2006). Vaginal douche practices among black women at risk: exploring douching prevalence reasons for douching and sexually transmitted disease infection. Sex Transm Dis, 33, 4, 215-9. [PMID:16565642]

Bradshaw, C. S., Morton, A. N., Garland, S. M., Morris, M. B., Moss, L. M., Fairley, C. K. (2005). Higher-risk behavioral practices associated with bacterial vaginosis compared with vaginal candidiasis. Obstetrics \& Gynecology, 106, 1, 105-14. [PMID:15994624].

Cankaya, S., Ege, E. (2014). Evli kadınların genital hijyen davranışlarının ürogenital semptomlar ile ilisskisi. Turkiye Klinikleri J Nurs Sci, 6, 2, 94-101.

Chalermchockchareonkit, A., Phoethong, S., Ruangvutilert, P., Thamkhantho, M. (2013). Prevalence of positive culture of genitourinary tract microorganisms in pregnant women with presumptive preterm labor. J Med Assoc Thai, 96, 9, 1111-1118. [PMID:24163985].

Cottrell, B.H. An updated review of of evidence to discourage douching. (2010). MCN Am J Matern Child Nurs, 35, 2, 102-7. [PMID:20215951].

Dongre, A. R., Deshmukh, P. R., Garg, B. S. (2007). The effect of community-based health education intervention on management of menstrual hygieneamong rural Indian adolescent girls. World Health Popul, 9, 3, 48-54. [PMID:18272942].

Dwyer, J. M. (2001). High-risk sexual behaviours and genital infections during pregnancy. Int Nurs Rev, 48, 4, 233-40. [PMID:11775757].

Ege, E., Eryılmaz, G. (2006). Kadınlara verilen planlı eğitimin genital hijyen davranışlarına etkisi. Anadolu Hemsirelike ve Sağhle. Bilimleri Dergisi, 9, 3, 8-16.

Ege, E., Timur, S., Zincir, H., Egri, M., Sunar Reeder, B. (2007). Women's douching practices and related attitudes in eastern Turkey. J Obstet Gynaecol Res, 33, 3, 353-9.

Er, S., Şirin, A. (2007). Gebelikte sağlık uygulamaları ölçeği türkçe formunun geçerlik ve güvenirlik çalışması. 5. Üreme Sağğğ ve Aile planlaması Kongresi, 19-22 June, Ankara.

Fakhri, M., Hamzehgardeshi Z., Hajikhani Golchin, N. A., Komili, A. (2012). Promoting menstrual health among persian adolescent girls from low socioeconomic backgrounds: a quasiexperimental study. BMC Public Health, 12, 193, 1-5. [PMID:22420743].

Farage, M.A., Lennon, L., Ajayi, F. (2011). Products used on female genital mucosa. Curr Probl Dermatol, 40, 90-100. [PMID: 21325843].

Ferraro, Z. M., Boehm, K. S., Gaudet, L. M., Adamo, K. B. (2013). Counseling about gestational weight gain and healthy lifestyle during pregnancy: Canadian maternity care providers' selfevaluation. Int J Womens Health, 30, 5, 629-36. [PMID:24109200].

Fonck, K., Kidula, N., Jaoko, W., Estambale, B., Claeys, P., Ndinya-Achola, J., at al. (2000). Of the vaginal discharge algorithm among pregnant and non-pregnant women in Nairobi, Kenya. Sex Transm Inf, 76, 1, 33-8. [PMID:10817066]. 
Çankaya, S., \& Dereli Yllmaz, S. (2015). Factors associated with Genital Hygiene Behaviours in pregnant and nonpregnant women in Turkey. International Journal of Human Sciences, 12(1), 920-932. doi: 10.14687/ijhs.v12i1.3126

Garg, R., Goyal, S., Gupta, S. India moves towards menstrual hygiene : subsidized sanitary napkins for rural adolescent girls-issues and challenges. (2012). Matern Child Health J. 16, 4, 767-774. [PMID:21505773].

Hacialioğlu, N., Nazik, E., Kiliç, M. (2009). A descriptive study of douching practices in Turkish women. Int J Nurs Pract, 15, 2, 57-64. [PMID:19335521].

Karatay, G., Özvarış, Ş. B. (2006). Bir sağlık merkezi bölgesindeki gecekondularda yaşayan kadınların genital hijyene ilişkin uygulamalarının değerlendirilmesi. C.U. Hemşirelik Yüksekokulu Dergisi, 10, 1, 7-14.

Kavlak, O., Saruhan, A., Er, S., Şen, E., Sevil, Ü. (2010). Gebelerin genital hijyen davranışlarının belirlenmesi. E.Ü. HYO Derg, 26, 1, 53-63.

Kisa, S., Taskin, L. (2009). Validity of the symptomatic approach used by nurses in diagnosing vaginal infections. J Clin Nurs, 18, 7, 1059-68. [PMID:19284438].

McClelland, R. S., Ndinya-Achola, J. O., Baeten, J. M. (2006). Is vaginal washing associated with increased risk of HIV-1 acquisition?. AIDS, 20, 9, 1348-9. [PMID:16511421].

Nair, M. K., Leena, M. L., Thankachi, Y., George, B., Russell, P. S. (2013). ARSH 1: Reproductive and sexual health problems of adolescents and young adults: a cross sectional community survey on knowledge, attitude and practice. Indian J Pediatr, 80, 2, 192-8. [PMID: 23934098].

Ocaktan, M. E., Baran, E., Akdur, R. (2010). Evaluation of habitual behavior related to genital hygiene in women living in a health care center area. Saudi Med J, 31, 11, 1251-6. [PMID:21063658].

Ott, M.A., Ofner, S., Fortenberry, J.D. (2009). Beyond douching: use of feminine hygiene products and STI risk among young women. J Sex Med, 6, 5, 1335-1340. [PMID:19170863].

Patel, V., Weiss, H. A., Kirkwood, B. R., Pednekar, S., Nevrekar, P., Gupte, S., at al. (2006). Common genital complaints in women: the contribution of psychosocial and infectious factors in a population-based cohort study in goa, India. Int J Epidemiol, 35, 6, 1478-85. [PMID:16997847].

Plumb, J., Clayton, G. (2013). Group B streptococcus infection: risk and prevention. Pract Midwife, 16, 7, 27-30. [PMID:23909200].

Polat, E., Sirekbasan, S., Yıldırım, Z., Bağdatlı, Y., Çepni, I., Çift, T., Baltalı, N. D. (2011). Comparing the occurrence of Trichomonas vaginalis infections today to ten years ago amongwomen prostitutes and gynecology and obstetrics patients in Istanbul. Turkiye Parazitol Derg, 35, 2, 68-71. [PMID:21776589]

Prasad JH, Abraham S, Kurz KM, George V, Lalitha MK, John R, at al. Reproductive tract infections among young married women in tamil nadu, India. Int Fam Plan Perspect. 2005;31(2):73-82. [PMID:15982948].

Ramia, S., Kobeissi, L., El Kak, F., Shamra, S., Kreidieh, K., Zurayk, H. (2012). Reproductive tract infections (RTIs) among married non-pregnant women living in a low-income suburb of Beirut, Lebanon. J Infect Dev Ctries, 17, 6, 9, 680-3. [PMID:23000869].

Yasmin, S., Mukherjee, A. (2012). A cyto-epidemiological study on married women in reproductive age group (15-49 years) regarding reproductive tract infection in a rural community of West Bengal. Indian J Public Health, 56, 3, 204-9. [PMID:23229212]. 